\title{
A Backdrop Case Study of AI-Drones in Indian Demographic Characteristics Emphasizing the Role of Al in Global Cities Digitalization
}

\author{
Purnima Lala Mehta ${ }^{1}$ D $\cdot$ Ramneek Kalra ${ }^{2} \cdot$ Ramjee Prasad $^{3}$
}

Accepted: 27 November 2020 / Published online: 2 January 2021

(c) The Author(s), under exclusive licence to Springer Science+Business Media, LLC part of Springer Nature 2021

\begin{abstract}
Urbanization of global populations with augmented and convenient living standards of people are driving towards techno-enabled and sustainable smart cities in the future. With this, technology plays a key role in making the existing cities smart and intelligent in a way that the citizens are being served better and safer. Over the past 1-decade, the application of Artificial Intelligence (AI) in different sectors like Environment, Education, Healthcare, etc. is well-supporting the idea of Global Digitalization and Smart Cities. In this paper, we highlight and discuss the multiple sectors where the AI approach is expected to grow to make a Global Smart City. Further, the paper contributes to presenting the AI approach for urban and rural India using AI-enabled drones. For Urban India, we discuss how and where the AI can be used to make urban India smart and sustainable. Lastly, the paper contributes to exposing the challenges faced by rural India and giving a wholesome approach to integrating AI into different sectors for rural enhancement and upliftment.
\end{abstract}

Keywords Smart cities · Global digitalization · Artificial intelligence $\cdot$ Urban India $\cdot$ Rural India

Purnima Lala Mehta

purnima.lala@gmail.com

Ramneek Kalra

kalraramneek@ieee.org

Ramjee Prasad

ramjee@btech.au.dk

1 IILM College of Engineering \& Technology, Greater Noida, India

2 Wipro Limited, Bangalore, India

3 CTIF Global Capsule (CGC), Department of Business Development and Technology, Aarhus University, Herning, Denmark 


\section{Introduction}

The human race, since its inception billions of years ago, has marched through different eras of growth and development. Each era had been posed with several challenges from survival to protection and maintenance and comfort and luxury. The growth of natural intelligence in the human mind has played a pivotal role in the attainment of the present form of lifestyle. The five basic senses have supported the growth of natural intelligence and played a pivotal role in the survival, protection, maintenance, and growth of individuals as well as the resources on the planet Earth.

The progress of the digit from a number to an activity. i.e. Digitalization is the result of Artificial Intelligence (AI) gained during the process of human evolution and growth. A certain quantum of intelligence is the basic nature of humans that is the essence of an individual while a lot more intelligence is acquired from the environment and circumstances that develop into personality and Artificial Intelligence. While the presence of human life on the planet is a natural phenomenon, the survival, maintenance, and comfort are the baby of the intelligent human mind. The activity of the human mind is a storehouse of information grasped through the five basic senses i.e. visual (eyes), auditory (ears), olfactory (nose), gustatory (tongue), and tactile (skin). In the nascent form of life, the natural intelligence supported the growth of the mind and empowered the humans with the power of C5 Concentration, Confidence, Creativity, Calmness and Contentment [1] that supported the growth and survival of the human race against all odds and protected it from extinction unlike a lot of other forms of life on Earth. This is depicted in Fig. 1 that shows the association of the basic senses, intelligence, and the $\mathrm{C} 5$. The creative growth of the human mind rendered means for survival, peace, protection, and maintenance as well as the comforts and luxuries.

In the present smart era of technology, the metamorphosis of the human race is evident in the environment and lifestyle of humans. Man has extended the activity of the mind to machines and created Artificial Intelligence or machine intelligence that is an extension of the five basic human senses. Smart gadgets are an extension of the basic senses and activity of humans. It has been a constant endeavor of technology to introduce inventions for the human senses like projectors and televisions for visuals, telephones, and microphones for auditory, perfumes, aroma, and sensors for olfactory, clothes, and garments for tactile and exquisite cuisines for the gustatory senses. Natural intelligence has been replaced by Artificial Intelligence. Survival, protection, and maintenance have been replaced by the comforts and luxuries of life. The rendition of day to day physical activities to machines by humans has created Artificial Intelligence that plays a predominant part in Global Digitalization. The communion of natural intelligence with existence has been replaced by the communion of artificial intelligence with global digitalization.

\subsection{Why Artificial Intelligence?}

With the growth of the human mind natural intelligence has gradually being transferred to machines and Artificial Intelligence or Machine Intelligence [2] is dominating the present lifestyle of the individuals. The commonly performed tasks by humans are rapidly being assigned to machines. The basic goals of AI are not restricted to learning, reasoning, and perception but are being extended to every minimal activity of human life [3]. The thinking machines that include complex information, automata, and cybernetics have invaded 


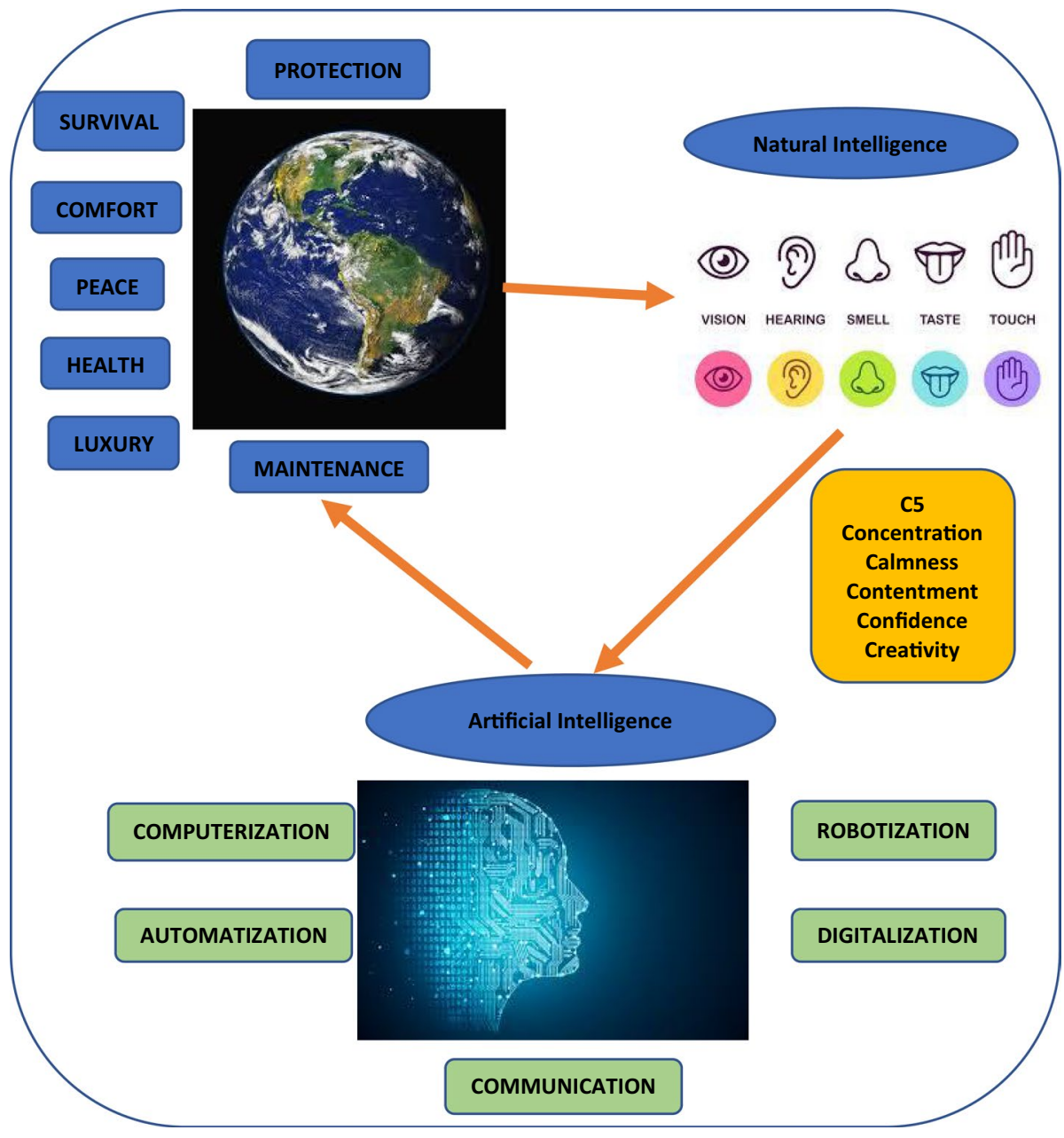

Fig. 1 Association of basic senses, intelligence and C5

every sector, industry, and business. Global Digitalization or a new era of global flow, a product of AI, has turned the planet into a global digital village. The world is unprecedently connected at the mere press of buttons. Global Digitalization has opened gates to all businesses from startups to small and large companies all have come together on the same platform and facing competition with each other. Amazon, Flipkart, Airbnb, Uber, and Ola are some of the significant startups that have grown with zero or minimal investment to companies with international businesses.

\subsection{Intelligent or Smart: People or Devices?}

The much talked about Artificial Intelligence is paving its way into every task where a human can have ease and comfort. A point of contemplation is how smart or intelligent can a device can become to just follow what it is being asked to. It is a human who needs to 
think, design, and create those artificial intelligent devices and it is a matter of discussion as to how smart a human is himself to make a wholesome of intelligent devices and make them work in unison and integration to perform specific tasks. Is it allowed for a computing device to decide and act on situations better than the humans themselves?

Moreover, having a smart device means it can compute and perform tasks according to whatever it is programmed for might not be necessarily an intelligent device. However, when we say a device is intelligent, means that apart from performing the tasks it is programmed for it can learn from its experiences and act in a better and strategic way for the upcoming tasks.

\subsection{Contribution of the Paper}

This paper is a well-thought attempt to frame together with the overview, present scenario, challenges, and solutions in context to apply AI in giving people of urban and rural India a smart, healthier and a strengthening life. The following are the contributions of the paper:

1. The paper highlights and discusses the multiple sectors where the artificial intelligence approach is expected to grow to make a Global Smart City.

2. The paper presents the artificial intelligence approach for urban and rural India as a case study.

3. For Urban India, we discuss how and where the artificial intelligence can be used to make urban India smart and sustainable.

4 The paper contributes to exposing the challenges faced by rural India and giving a wholesome approach to integrating artificial intelligence into different sectors for rural enhancement and upliftment.

5. Lastly, we also add our views on how AI can be used post-COVID for handling Urban and Rural India challenges in healthcare.

\section{Role of Al in Global Cities Digitalization}

The different sectors that this study deals with are as following:

- Healthcare management

- Education management

- Environment management

- Infrastructure management

- Network management

- Power/energy management

- Urban traffic/transport management

- Civil safety and security

- Catastrophe management

AI will be involved in every field, every sector in the coming years of global digitalization. As referenced in Forbes Technology Council Post [4], AI will soon revolutionize industries including Cybersecurity, DevOps, Manufacturing, Healthcare, Construction, Senior Care, Retail, Business Intelligence, City Planning, Mental Health Diagnosis and Treatment, Education, Fashion and Supply Chain Management. The application of AI is 
not limited to chatbots, Intelligence systems, digital-healthcare, etc. but will surely expand its capabilities and applications in the above-mentioned fields (Fig. 2).

\subsection{Healthcare Management}

Healthcare is a major field of AI application, especially since the COVID-19 scenario broke out. Even the developed nations have struggled to cope with the pandemic and to provide ample healthcare professionals, medicines, equipment, and machinery. There is a deluge on research activities due to COVID-19 and AI with impactful-ness is being proposed for establishing new and smart solutions for hospitals, clinics, and connected healthcare belts. Medical research is working on analyzing and identifying patterns in various complex large datasets faster and more efficiently than previously possible [5]. For many researchers making predictions is the most demanding field of medical science, image classification for the prediction of root cause where the disease has started can also be seen [6].

Healthcare Management is also working under developing IOT Based AI Solutions, for which many authors have proposed their architecture and solutions. As Jochen [7] discussed the platform approach to the Smart Living for medical as well as a smart home living. With the advancement of the same, societies may need to face the challenges and the privacy issues which is being discussed by Ibrahim [8] with taking care of the challenges that IOT Sleep trackers and privacy \& security concerns lied by sharing this data with companies holding the responsibility of serving resources. With that approach, Ibrahim discussed with the best approach from the privacy angle as to use the sensing approach (SA), Awareness and Security (AS) for End-Users, Cloud Environment.

\subsection{Education Management}

With the most dealt sector from the AI perspective is this sector, where researchers as well as many organizations are building their custom solutions to serve the best solution for education purposes. So, research is also going on to build better AI Solutions to automate

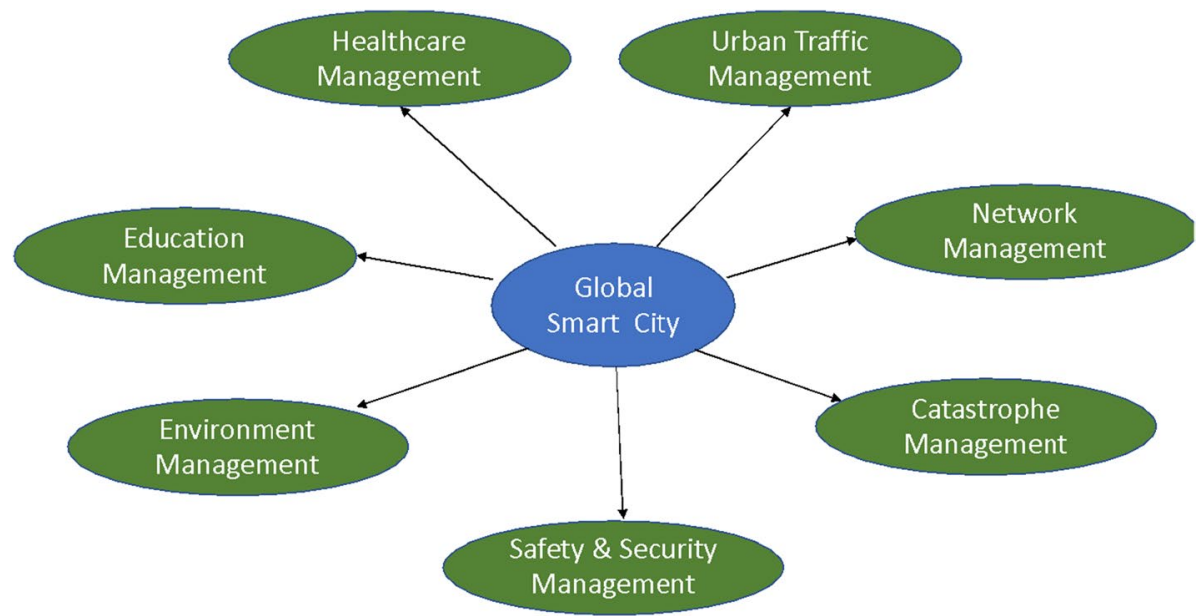

Fig. 2 Global smart city sectors 
the process of allocation of subjects, lectures, and other related things in hand with the advancement of classrooms. Sutjarittham [9] contributes by undertaking the evaluation of several approaches that involve IoT as the core model, for measuring classroom occupancy and manipulating this based on terms including cost, accuracy, privacy, and ease of use.

With the need for smart tutors, researchers too proposed some concrete solutions from where AI Tutors can help them to allot resources so that they can grasp the concepts inhand efficiently and effectively. Francisco [10] discussed the approach for their designed algorithm that helps them to articulate profiles of students based on their historical records and then recognizing the candidate that encounters to personalize their smart tutoring experience taking into consideration for the similar candidates.

\subsection{Environment Management}

When technological innovation is used for the advancement of the society for smart innovation, every sector comes into context, similarly, the Environment plays an important context when one is considering AI to be used in Smart Cities Strategy plan. This sector deals with the management of controlling and eliminating pollution including air, noise, water, etc. from the environment. For this context, the ways by which AI can be used and get linked with Pollution management is the main concern of understanding. Many environmentalists and researchers are working on many new innovative solutions that can understand the patterns and learn on their own to predict and eliminate the density of pollution around. For many purposes, electro-static precipitators are used commonly for filtering dust particles to control air pollution, but they are also challenged beyond their specifications, for which Bazzi [11] discussed the approach of using ANN and random forest approach to improve the quality of these precipitators.

\subsection{Network Management}

The most needed resource in today's digital era is becoming for sure is Networking and communication among surroundings. With that, dealing with a huge amount of data surely comes with the analysis of the same, where only AI plays an important role. Communication among humans, machines, vehicles or related smart node, comes with new challenges to use it efficiently, where AI modeled itself to introduce with new approaches on which network engineers and AI Engineers are working on these days. CISCO is the parent company for the networking field, introduces AI Solutions for the B2B approach for networking in business maintenance and communication with customers [12].

\subsection{Power/Energy Management}

Power/Energy Management is the base demand for the digitalization for cities and this can be fulfilled mainly in contrast under the use of Artificial Intelligence. Power/Energy Management deals with the management and maintenance of Energy Equipment and monitoring these with full efficiency. But, due to human prone errors in the management, many encounters suffer from the incidents. For solving this problem, an artificially intelligent system is mandatorily required with a full-fledged solution for the demand as well as supply. 
Covering the recent research works, many worked and implemented different AI Models to deploy smart solutions for the household energy storage systems, Microgrid Applications, Energy Buildings, and many more included. With the coming trend in the use of AI in Power/Energy Management, Energy Internet is the coined term used by most of the researchers across the globe, this term is the key research hotspot for many of the researchers with their meaning to Energy Internet. Pointing to this term, Cheng [13] explains briefly the term and its related equipment systems that can be integrated to serve the purpose of delivering smart and connected solutions of Energy Management. On the other hand, deploying AI in smart energy systems can also be integrated as Sun [14] discussed in their paperwork. Their paper proposed a smart classification method that combines the intelligence of an Independent Energy Unit with Interconnected Energy Unit which resulted in the development of an AI Technique for energy systems.

\subsection{Urban Traffic/Transport Management}

Traffic as one of the daily routines dealt with problems across the globe is reaching its heights and deploying of self-driven vehicles won't help the living anymore if that's fully automated and being learned to compare with the rapidness of human-operated vehicles. Traffic Management is one of the top concerns which can be controlled, even eliminated with the proper usage of AI. Many researchers are working on the advancement of the same concern including [15], which describes the application of AI in Transportation systems as planning, Designing and controlling Transportation Network Structures, Incident Detection, Predictive models, and throw light on the need of Intelligent Urban Mobility. Moreover, AI in Traffic needs to get integrated with other technologies that are included with Data, various works implemented the use of Cloud and AI to give a concrete application of AI to build smart solutions for managing traffic in their surroundings. As Telegra Inc., USA deployed their TCC 2.0 (Traffic Control Centres) [15] across Russia Regions [16]. Techniques including Dynamic Lane Assignment (DLA) [17], Vehicle-to-Everything [6], Autonomous Vehicles by using Network Calculus (NC) [7], Deep Neural Network [8] and many more. The challenge for every country is to work on the development of a universal approach that Traffic and Transport Management can be solved.

\subsection{Civil Safety and Security}

Crime being the darker end of any country is to one of the sectors where AI can be applied and proper analytical with forecasting of crimes can be seen. Similarly, Security and Safety Management becomes an urgent need to be getting used by various Crime Investigation Departments/Smart Homes. Various applications of AI are being seen under this Sector including public safety video and image analysis, DNA Analysis, gunshot detection, and crime forecasting [18], mainly researched by the National Institute of Justice. Inclusion of Safety AI Cameras can be deployed to ensure the safety of one's home members as worked together by.

\subsection{Catastrophe Management (Surveillance and Rescue Missions)}

This sector includes the management of climate change, disaster management, emergency conditions, and included factors. As the need for the AI in Emergency automation 
is required, similarly introduction of smart solutions is required in parallel. For the same, many researchers are working rigorously in this sector, Mohammad [19] discussed the approach of using Markov Decision Algorithm to obtain a fast and short pathway to the emergency spot by making AI-based Units namely, Emergency Management Unit (EMU). Similarly, communication becomes very necessary when disaster scenarios occurred and manual communication through humans becomes very less due to a stressed situation, for the same then required for an AI-based communicator is needed, Okamoto [20] discussed this approach through a solution for connecting networks from image classification surveillance system which depends upon the content inputted through camera and Information-centric network then communicates to the disaster management team to help with the situation. Then the need of making this more meaningful, researchers worked onto using external solutions provided by cloud vendors like IBM Cloud Service as reflected by Talley [21] who illustrates the fact of making awareness among connected societies so that make surrounding aware regarding the disaster occurred and sharing same with disaster rescue team using cognitive cloud approach.

\section{Al Applications Globally}

With the advancement of AI in different sectors, it comes that each country across the globe is contributing to making their ranking more under this AI Space. In the same way, many researchers are reviewing their approaches and leading to many conclusion points. Table 1 gives insight for top countries working on their practical AI models to stand apart in the AI Market. Including the USA, Europe, and China all has AI Policies released recently. USA declared the executive order as "Maintaining American Leadership in Artificial Intelligence" [22] and similarly, China released State Council Notice regarding the plan of actions in AI [23].

\section{Al-Drone Approach in Urban India}

In this section, we will put forward a case study for Urban India and discuss how AI-enabled drones can be useful to Urban people in multiple sectors like Healthcare, Education, Environment, Network, Power/Energy, and in urban traffic/ transport.

\subsection{Healthcare}

Provisioning of medical facilities door to door will be one thing that drones would be capable of doing, especially in an emergency driven situation where the regular facility is not fast enough to reach. Drone Air Ambulances can be specifically used in rural and remote areas with inconvenient hospital emergency facility. Drones can be used for carrying and supplying organ transplants, testing samples, blood, medicines, etc. in a need-based situation. Drones can also act as a smart caregiver to an old-age home or paralyzed patients, provide them medicines and healthcare facilities regularly in time as well as during distress conditions. In collaboration with the Serum Institute of India (SII), the Maharashtra government is in an agreement with private drone operator Zilpline to use drones in remote areas for medical emergencies [33]. 


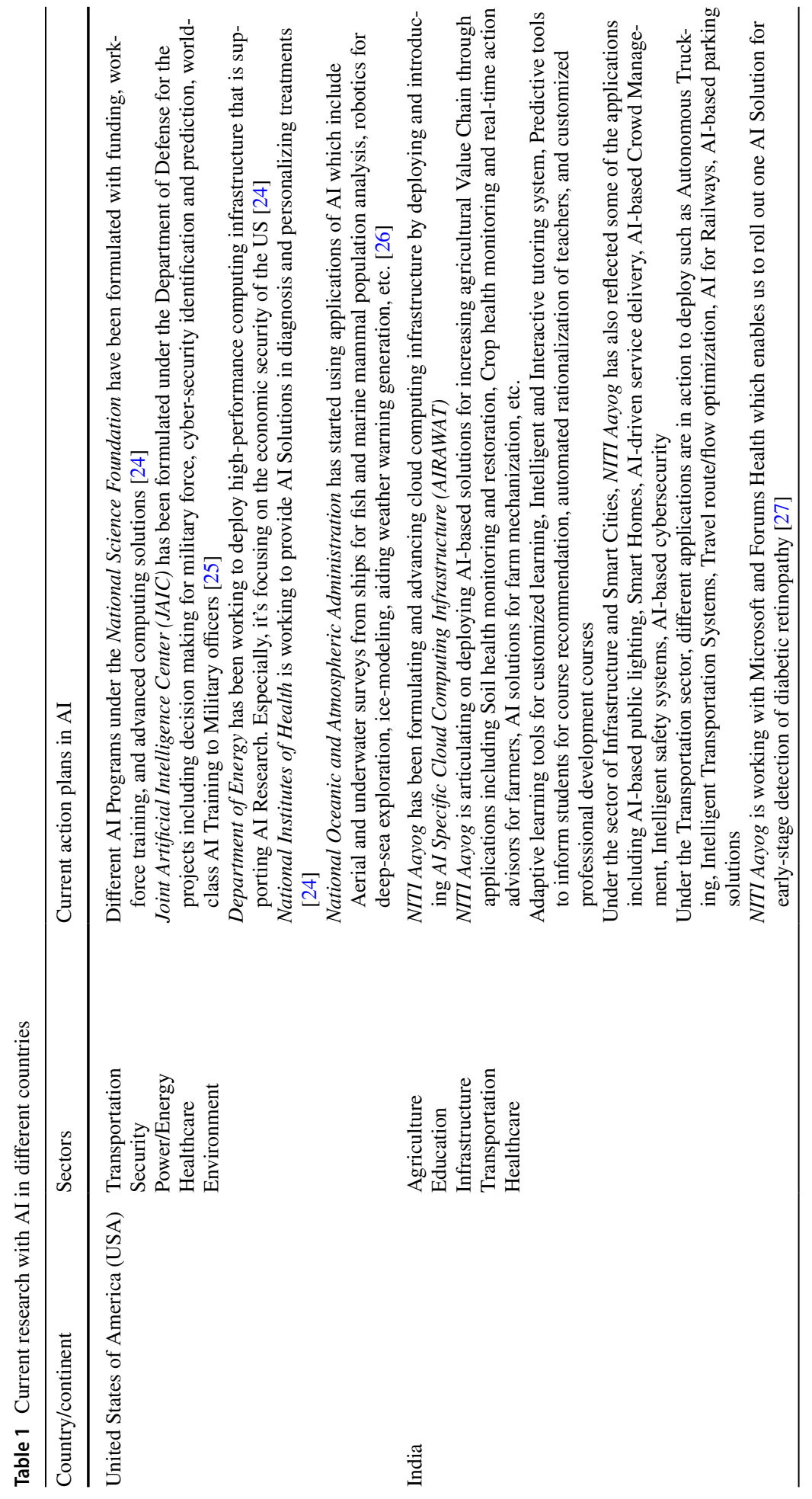




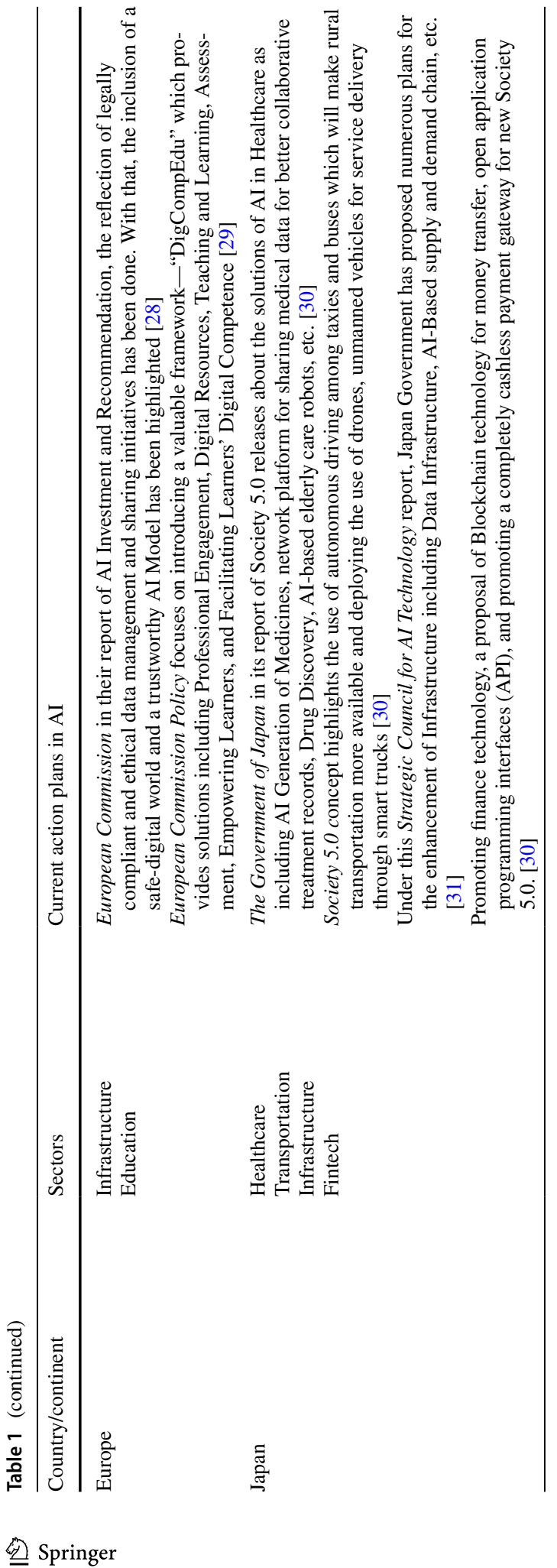




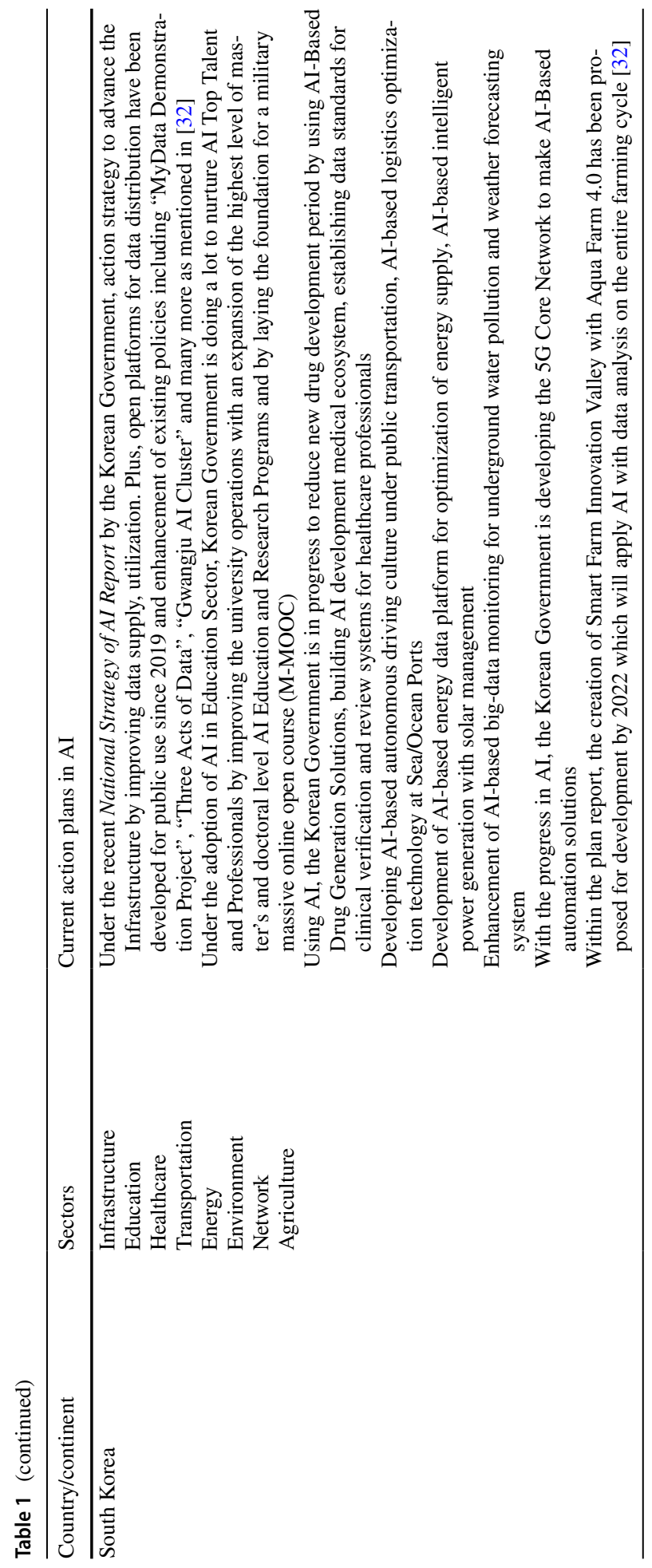


Talking of the present Corona Virus Disease (COVID) scenario, drones can be used to sanitize a completely urban area, including narrow lanes and congested residential areas. The AI will play a role in making the drones intelligent to sense how safe a particular zone is, thereby spraying the sanitizer more effectively without any wastage. AI-drones can carry plasma therapy equipment, blood samples, other medicines, etc. in cases where human outreach is time-consuming.

\subsection{Education}

It is a fun task to introduce drones in the field of education. For instance, drones can be used to connect the outside real world to the classrooms inside. Drones can take pictures and students can make stories, learn concerning real-life examples that will help to learn interactively and interestingly. Calculations on traveling distances, power vs payload, time-lapses, etc. can be performed better using the drones. Science students can study aerodynamics, motoring, etc., and make drones projects for multiple applications. The outcome will be an effective teaching and learning method apart from the regular bookish coaching. Though nothing concrete has come up to bring drones into the Education sector in India Drone Schools have been set up for giving training on drone flying and a similar setup can be done in schools for training drone flying as part of the regular curriculum.

\subsection{Environment}

Air pollution is a big problem in many of India's metropolitan cities. Burning of garbage waste, crops, plastics, crackers, etc. contribute to deteriorating the Air Quality Indicator (AQI), apart from vehicular and industrial emissions. Drones can be used to keep a check on the intensity of smoke being generated in the air at faulty areas and reporting to the authority to act upon. Bush and crop burning are difficult to control once starts and early reporting can result in curbing high pollution levels. The Environment Pollution (Prevention and Control) Authority (EPCA) are proposing drones with monitoring capabilities and act as a Watchdog [34]. Further, talking about water pollution, AI Drones with satellite imagery could be deployed in near future to monitor pollution levels of the rivers like the Yamuna caused by dumping of debris at the flood plains of the river [35].

\subsection{Network}

The cellular networks that are available in India are not commensurable during congestions at dynamic hotspots where the mass gathering of people is observed $[35,36]$. Festivals in India are an important part of the celebration were making calls, videos, send messages, updating live statuses have become quite common. Drone Base Stations working in teams as Aerial-Heterogeneous Networks [37, 38] can provide extended assistance to the ground base stations to relieve temporary congestions. Building and deploying Drone Base Stations are at a nascent stage in India and research is being carried by DRDO, ISRO, and some other telecom companies. 


\subsection{Power/Energy}

Explicit use of drones in power management is not defined. However, power towers and poles images can be taken by drones for inspection purposes [39]. Manual intervention in such cases is not accurate and can be risky. Power theft is a concern in India and smart policing and reporting can be performed by drones. Sterlite Power and Sharper Shape are in talks with the Directorate General of Civil Aviation, India (DGCA) to deploy long-distance drone flights to provide safe, efficient, and fast inspection methods [40].

\subsection{Urban Traffic/Transport:}

Drones can have multiple uses in urban traffic management. To control traffic on busy roads and let the ambulances pass by smoothly, drones have been proposed. The drone will sound a siren and fly ahead of the travel path of the ambulance to clear its path. Uber is also considering launching Drone Air Taxis as a measure to curb traffic snarls, especially during peak hours. Further drones can give a 'bird's eye view' and investigate behavior and routes of traffic and understand the cause of accidents, slow-downs, etc. [41].

\section{Al for Rural India Upliftment}

AI is playing a predominant role in the Global Digitalization. It is pertinent that the rural areas in India should also get a fair share in marching shoulder to shoulder with their urban counterparts. AI can contribute in more than one way for rural upliftment. Each sphere of rural life can witness a metamorphosis with AI. Unfortunately, the penetration of AI is still under the amateur phase and needs significant research and attention in multiple applications where AI can be used extensively.

Figure 3 demonstrates four major areas namely Education, Agriculture, Healthcare, Network and Infrastructure where AI can come into play, burgeoning Smart Village concept in India.

\subsection{Agriculture}

For rural India, Agriculture is the most important aspect of sustainability and survivability for the farmers. Some new generation people are leaving the villages for smart cities and it is a loss to the agriculture industry. It is difficult for the older population to take care of the fields and crops. An important point to note is that the farmers in rural villages are illiterate and unaware of the advances that are already being implemented in urban counterparts. These farmers and their families can be trained by AI specialists initially and once the understanding of the AI operations is made, the farmers can train other people of their villages and their upcoming generations. In this way, a learning direction amongst the younger generation will rise and give them opportunities to earn while staying in their home villages.

Talking about AI technology, Drones embedded with AI algorithms can be applied to rescue the farmers in giving a view of the fields and the crops in the fields. An example of using drones in rural areas is illustrated in Fig. 4.

The use of robots for paddy plantation is another method that can save on tedious human and livestock labor and ensure accuracy. Further, the use of sensors in stores and 


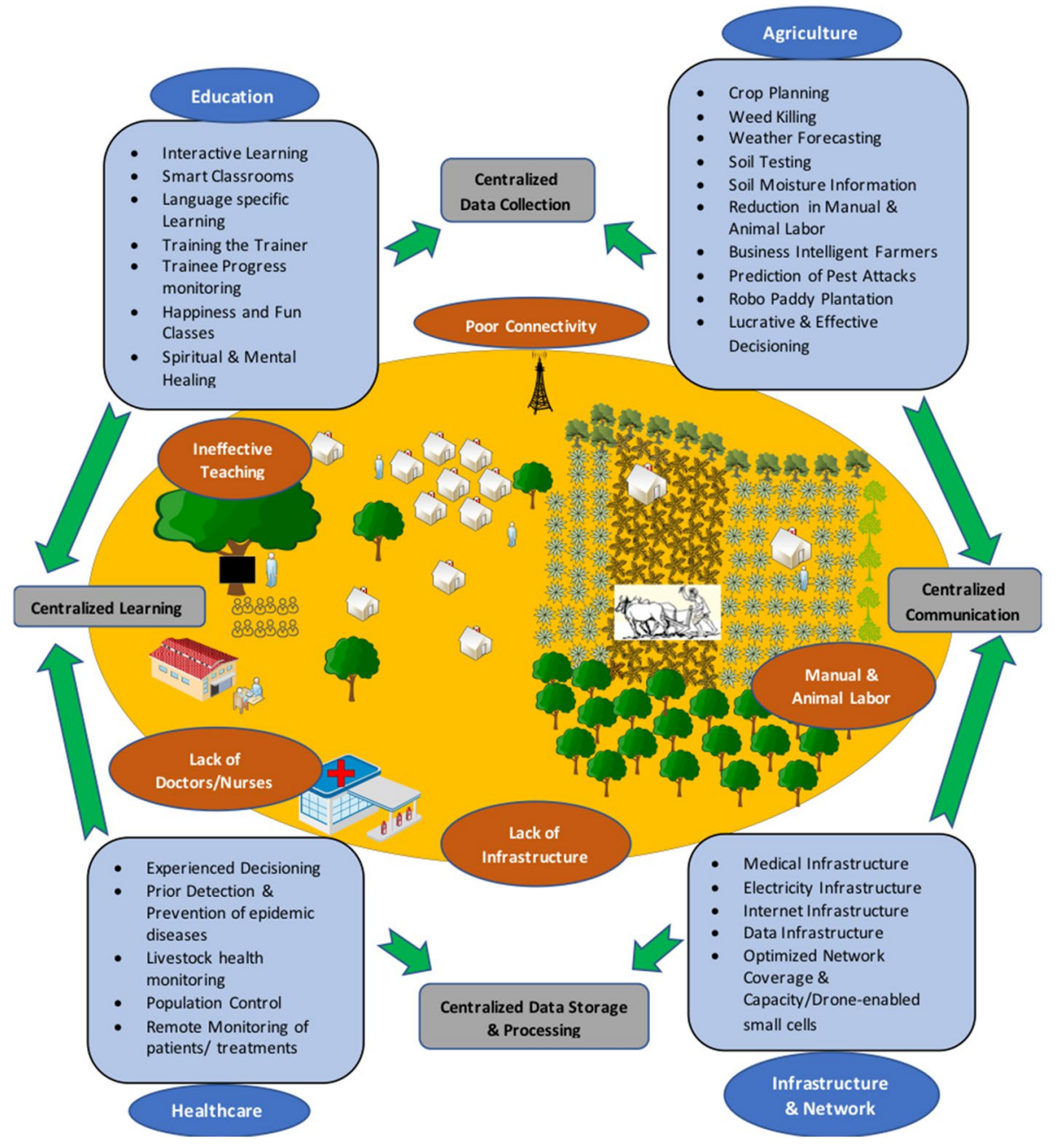

Fig. 3 AI applications for rural India

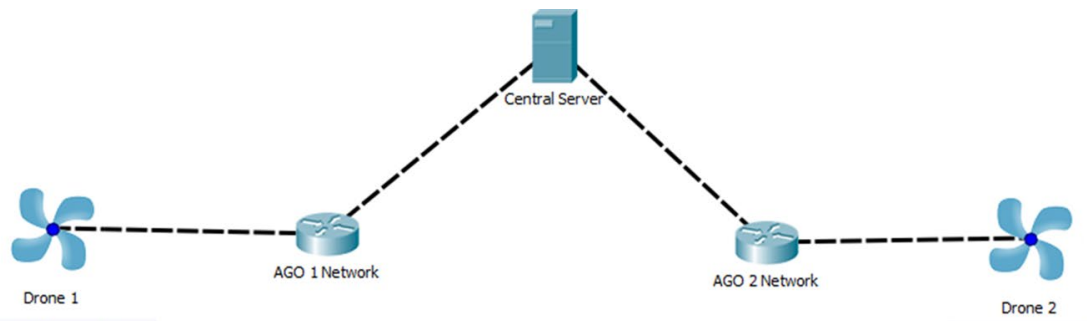

Drone 1 Collects village 1

Farms Data and analyze it

Drone 2 Collects Village 2

Farms Data and analyze it

Server

on-spot to send to Central

Fig. 4 Centralized drone data collection 
warehouses can help to protect the produce from possible damage from insects and rodents. A centralized communications and data system can help a cluster of small villages to keep a record of the products available and the ways to market and transport it. AI embedded sensors can be planted in the fields to give an update and alarms on the status of crop growth, water levels, weed growth, etc.

There are some other applications where AI can be exploited in rural agriculture:

- Crop planning This can be done using Drone analyzed framed data onto drone OS itself, using Image processing algorithms like [26] showcased the use of OpenCV Library. With that, the drone can analyze its node itself regarding crop planning, making decisions about buying products quickly.

- Weather forecasting This can also be achieved by installing environmental sensors onto the drone surface which can predict the upcoming disaster if any onto the Farmer System (Mobile).

- Soil related issues This can also be completed by having smart soil detection cards like Soil Health Card [27]

- Business intelligent farmers AI can help farmers to learn their selling patterns and give better decisions on their future sales. This will ensure a lucrative business to the farmers and make them business intelligent.

\subsection{Healthcare}

Healthcare is of eminent importance for the rural areas as the existing healthcare facilities are negligible or minimal. Being remote places, the accessibility to doctors, nurses, hospitals, medicines, etc. is nethermost. AI can be used to create virtual dispensaries and therapy procedures that can help tackle the health problems of rural people. This can be achieved using smart solutions available to rural area citizens through websites or android applications. Again a team of AI specialists would be required to work in the rural areas on a shift basis. Connected health data manipulation systems (refer Fig. 5) can also be used where a patient can seamlessly communicate with a doctor's network connected in Urban Market, enhancing the connected health paradigm as well as eliminating issues arising due

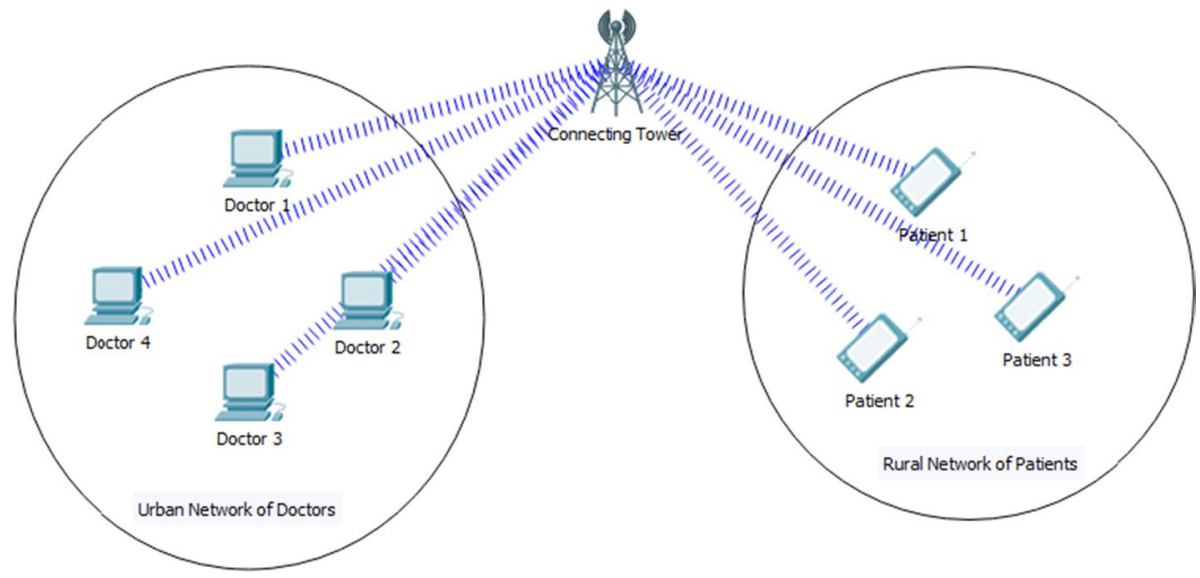

Fig. 5 Connected health data manipulation system 
to ineffective and untimely decisions taken under critical and emergencies. More often, deploying a network of emergency services in rural areas can enhance the quick actions to be required during the instant through the drone ambulance system [42]. This will enhance the real-time monitoring and connections altogether with emergency departments too.

Talking about the COVID situation prevailing in current times, we see that the poor people are the most affected. They are deprived of basic medical facilities, ambulance services, and healthcare teams visiting villages with a fear of contact with a COVID positive person. Again, in such cases, AI-drones can act as smart nurses, take blood samples, deliver reports and equipment to the critically ill patients in cases where human presence would be completely replaced.

Similarly, livestock health monitoring can also be tackled using body sensors on cows, goats, etc. which can provide on-spot analysis of information i.e. body temperature, health status, beats per minute, etc. This data can then be sent out to veterinarians nearby to enable instant support and treatment.

\subsection{Education}

Education is the primary source of development of any society across the globe, which must be delivered with a seamless experience and huddle less. The educational issues can be resolved by using AI and STEM (Science, Technology, Engineering, and Mathematics) as the important resources to provide to every student of the rural area through online live video classrooms, remote login into urban-based researching/studying tools, etc. More often, deploying AI-based Kiosks around classrooms in rural areas can build up the learning process quicker with the following features:

- Regional based language training

- Social problems awareness

- Fun learning activities and games

- Happiness classes

- Spiritual and mental learning

\subsection{Network and Infrastructure}

As of now, urban areas in India are struggling to receive good 4G coverage due to heavy subscribers' base. But this problem is not prevalent in rural areas where the population is minimal. With the available $2 \mathrm{G}$ or $2.5 \mathrm{G}$ network coverage in rural areas analyzing data on the cloud is somewhat improbable. For this problem, we suggest an appropriate solution wherein an existing model can be applied adding features of AI and IoT. We present a Fog Computing Model where the data is analyzed offline at the Application Layer and works by extending the computing to the edge of a network. This enables the computation to take place beyond just online. As illustrated in Fig. 6, all important aspects including medical, electricity, internet, data, and AI drone infrastructure can be designed with offline analysis using the Fog Computing Model. The required resources can be used effectively without buying an extra bandwidth.

For instance, if a drone-enabled service is to be used, drones can be populated across regions and all image processing and sharing of data to the users can be done on its operating system and passed through User Layer. 


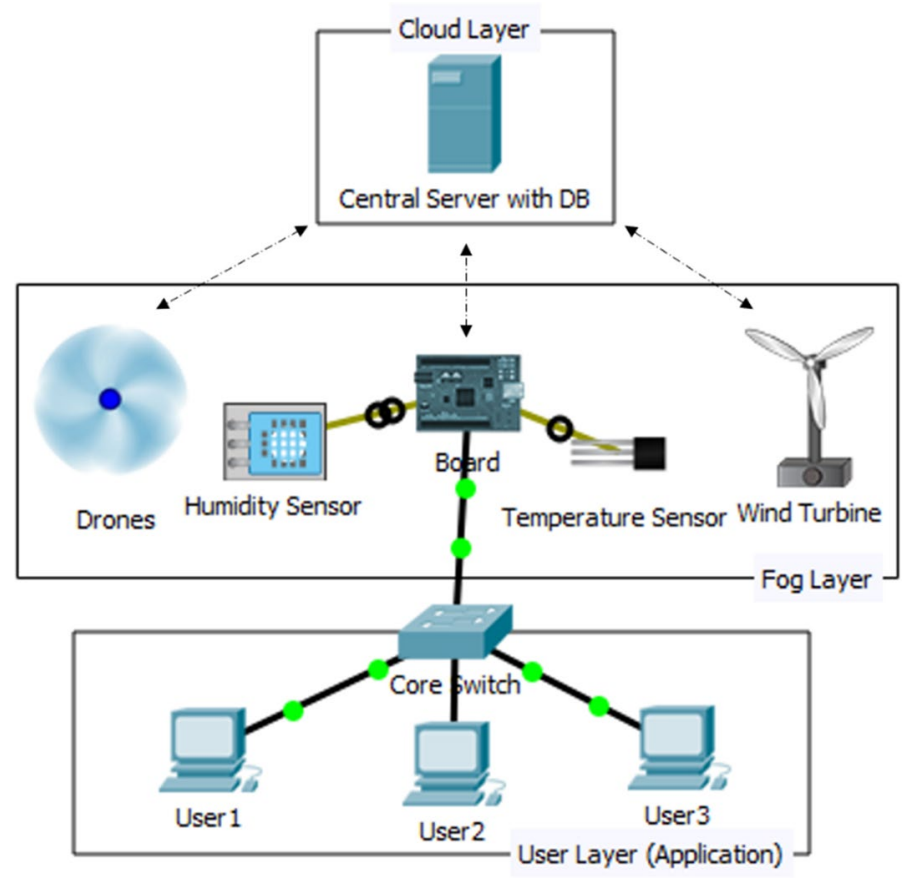

Fig. 6 Fog computing model for network with low bandwidth

\section{Conclusion}

The world is preparing to experience a digital transformation that requires proper research analysis, planning, and executions. While a majority of countries have put forward their plans, one of the major common points is the applications of Artificial Intelligence (AI) in the fields of Healthcare, Education, Environment, Infrastructure, Network, Power/Energy, Urban Traffic/Transport, Civil Safety \& Security and Catastrophe Management. AI penetration into multiple applications for service, security, maintenance, assistance, and sustainability will make the world living better and smart. However, some challenges need attention to populated countries like India. While urban India has started paving its way of implementing AI solutions, we present and discuss how drones can be utilized in the future and advance the existing methods and technologies. Further, Indian villages fall in a differential category in terms of environment, culture, and upbringing, there are challenges to consociate AI into remote and rural India. We have presented our viewpoint and approach in tackling the issues using AI technology, Fog Computing, and Centralized Data collection in the areas of Healthcare, Education, Agriculture, and Network/Infrastructure.

\section{References}

1. Prasad, R. (2012). Unlock your personalization. Aalborg: Aalborg University Press.

2. Artificial intelligence - Wikipedia. (n.d.). Retrieved May 5, 2020, from https://en.wikipedia.org/wiki/ Artificial_intelligence. 
3. Frankenfield, J. (n.d.). How artificial intelligence works. Investopedia. Retrieved May 5, 2020, from https://www.investopedia.com/terms/a/artificial-intelligence-ai.asp.

4. Council Post: 13 Industries Soon To Be Revolutionized By Artificial Intelligence. (n.d.). Retrieved May 5, 2020, from https://www.forbes.com/sites/forbestechcouncil/2019/01/16/13-industries-soonto-be-revolutionized-by-artificial-intelligence/\#7f4f7bab3dc1.

5. Leung, M. K. K., Delong, A., Alipanahi, B., \& Frey, B. J. (2016). Machine learning in genomic medicine: A review of computational problems and data sets. Proceedings of the IEEE, 104(1), 176-197. https://doi.org/10.1109/JPROC.2015.2494198.

6. Tong, W., Hussain, A., Bo, W. X., \& Maharjan, S. (2019). Artificial intelligence for vehicle-toeverything: A survey. IEEE Access, 7, 10823-10843. https://doi.org/10.1109/ACCESS.2019.28910 73.

7. Cui, Q., Wang, Y., Chen, K.-C., Ni, W., Lin, I.-C., Tao, X., \& Zhang, P. (2019). Big data analytics and network calculus enabling intelligent management of autonomous vehicles in a smart city. IEEE Internet of Things Journal, 6(2), 2021-2034. https://doi.org/10.1109/JIOT.2018.2872442.

8. Li-Zeyu, F., \& Ge-Xiaoyu, S. (2019). Prediction and analysis of road traffic efficiency based on DBN-SVR. In 2019 1st international conference on industrial artificial intelligence (IAI) (pp. 1-6). https://doi.org/https://doi.org/10.1109/ICIAI.2019.8850814.

9. Experiences With IoT and AI in a Smart Campus for Optimizing Classroom Usage - IEEE Journals \& Magazine. (n.d.). Retrieved May 5, 2020, from https://ieeexplore.ieee.org/document/8656525.

10. Azeiteiro, F., \& Lopes, M. (2019). Between clones and snow-flakes: Personalization in intelligent tutoring systems. In P. Moura Oliveira, P. Novais, \& L. P. Reis (Eds.), Progress in artificial intelligence (pp. 15-26). Cham: Springer. https://doi.org/10.1007/978-3-030-30241-2_2.

11. Bazzi, T., \& Zohdy, M. (2018). Artificial intelligence for air quality control systems: A holistic approach. In 2018 twentieth international Middle East power systems conference (MEPCON) (pp. 25-32). https://doi.org/https://doi.org/10.1109/MEPCON.2018.8635295.

12. Redefine Businesses with Artificial Intelligence. (n.d.). Retrieved May 5, 2020, from https://disco ver.cisco.com/en/us/digital-transformation/whitepaper/ai-whitepaper.

13. Cheng, L., Yu, T., Jiang, H., Shi, S., Tan, Z., \& Zhang, Z. (2019). Energy internet access equipment integrating cyber-physical systems: Concepts, key technologies, system development, and application prospects. IEEE Access, 7, 23127-23148. https://doi.org/10.1109/ACCESS.2019.2897712.

14. Sun, Q., \& Yang, L. (2019). From independence to interconnection-A review of AI technology applied in energy systems. CSEE Journal of Power and Energy Systems, 5(1), 21-34. https://doi. org/10.17775/CSEEJPES.2018.00830.

15. Glad, B. (n.d.). Next-generation traffic control, 2.

16. cms_page_320_file.pdf. (n.d.). Retrieved from https://www.telegra-europe.com/assets/cms_page_ file/cms_page_320_file.pdf.

17. Assi, K. J., Ratrout, N. T., \& Gazder, U. (2019). Quick optimal lane assignment using artificial neural networks. In 2019 international conference on innovation and intelligence for informatics, computing, and technologies (3ICT) (pp. 1-6). https://doi.org/https://doi.org/10.1109/3ICT.2019.8910323.

18. Using Artificial Intelligence to Address Criminal Justice Needs. (n.d.). National Institute of Justice. Retrieved May 5, 2020, from https://nij.ojp.gov/topics/articles/using-artificial-intelligence-addresscriminal-justice-needs.

19. Mohammad, N., Muhammad, S., Bashar, A., \& Khan, M. A. (2019). Formal analysis of humanassisted smart city emergency services. IEEE Access, 7, 60376-60388. https://doi.org/10.1109/ ACCESS.2019.2913784.

20. Okamoto, K., Mochida, T., Nozaki, D., Wen, Z., Qi, X., \& Sato, T. (2018). Content-oriented surveillance system based on ICN in disaster scenarios. In 201821 st international symposium on wireless personal multimedia communications (WPMC) (pp. 484-489). https://doi.org/https://doi. org/10.1109/WPMC.2018.8712852.

21. Talley, J. W. (2020). Disaster management in the digital age. IBM Journal of Research and Development, 64(1/2), 1:1-1:5. https://doi.org/10.1147/JRD.2019.2954412.

22. 2019-02544.pdf. (n.d.). Retrieved from https://www.govinfo.gov/content/pkg/FR-2019-02-14/ pdf/2019-02544.pdf.

23. China's New Generation of Artificial Intelligence Development Plan. (2017). FLIA. Retrieved from https://flia.org/notice-state-council-issuing-new-generation-artificial-intelligence-development-plan/.

24. American Artificial Intelligence Initiative: Year One Annual Report. (n.d.), 36.

25. SUMMARY-OF-DOD-AI-STRATEGY.pdf. (n.d.). Retrieved from https://media.defense.gov/2019/ Feb/12/2002088963/-1/-1/1/SUMMARY-OF-DOD-AI-STRATEGY.PDF.

26. LinkClick.pdf. (n.d.). Retrieved from https://nrc.noaa.gov/LinkClick.aspx?fileticket=0I2p2-Gu3rA $\% 3$ D\&tabid $=91 \&$ portalid $=0$. 
27. AIRAWAT_Approach_Paper.pdf. (n.d.). Retrieved from https://niti.gov.in/sites/default/files/2020-01/ AIRAWAT_Approach_Paper.pdf.

28. smuhana. (2018). High-level expert group on artificial intelligence. In Shaping Europe's digital future-European Commission. Text. Retrieved May 11, 2020, from https://ec.europa.eu/digital-singl e-market/en/high-level-expert-group-artificial-intelligence.

29. Team, F. (2017). European framework for the digital competence of educators: DigCompEdu. EU Science Hub-European Commission. Text. Retrieved May 11, 2020, from https://ec.europa.eu/jrc/ en/publication/eur-scientific-and-technical-research-reports/european-framework-digital-competence -educators-digcompedu.

30. society_5.0.pdf. (n.d.). Retrieved from https://www.japan.go.jp/abenomics/_userdata/abenomics/pdf/ society_5.0.pdf.

31. Artificial Intelligence Technology Strategy.pdf. (n.d.). Retrieved from https://www.nedo.go.jp/conte nt/100865202.pdf.

32. National Strategy for Artificial Intelligence_200323.pdf. (n.d.). Retrieved from https://english.msit. go.kr/cms/english/pl/policies2/_icsFiles/afieldfile/2020/03/23/National\%20Strategy\%20for\%20Art ificial\%20Intelligence_200323.pdf.

33. Maharashtra to deploy drones for emergency medical supplies. (2019). Hindustan Times. Retrieved May 10, 2020, from https://www.hindustantimes.com/cities/maharashtra-to-deploy-drones-for-emerg ency-medical-supplies/story-jOkOEkeaehwmIFzwT7BqcN.html.

34. Delhi pollution body plans to use drones to strengthen monitoring. (2019). Hindustan Times. Retrieved May 10, 2020, from https://www.hindustantimes.com/delhi-news/dpcc-planning-to-use-drones-formonitoring-delhi-pollution-hotspots/story-vJYVaVdEsMczjyK49CUuVO.html.

35. Kumar, A., Mehta, P. L., \& Prasad, R. (2014). Place time capacity-A novel concept for defining challenges in 5G networks and beyond in India. In 2014 IEEE global conference on wireless computing \& networking (GCWCN), Lonavala, India (pp. 278-282). IEEE. https://doi.org/https://doi.org/10.1109/ GCWCN.2014.7030894.

36. Kumar, A. (2016). Active probing feedback based self configurable intelligent distributed antenna system: For relative and intuitive coverage and capacity predictions for proactive spectrum sensing and management. Ph.D. Dissertation, Aalborg Universitet.

37. Drones, AI can be used to monitor Yamuna: NGT-constituted panel - The Hindu. (n.d.). Retrieved May 11, 2020, from https://www.thehindu.com/news/national/drones-ai-can-be-used-to-monitor-yamun a-ngt-constituted-panel/article26166999.ece.

38. Mehta, P. L., \& Prasad, R. (2017). Aerial-heterogeneous network: A case study analysis on the network performance under heavy user accumulations. Wireless Personal Communications, 96(3), 3765-3784. https://doi.org/10.1007/s11277-017-4283-3.

39. Zhang, Y., Yuan, X., Li, W., \& Chen, S. (2017). Automatic power line inspection using UAV images. Remote Sensing, 9(8), 824. https://doi.org/10.3390/rs9080824.

40. Sterlite Power And Sharper Shape Use Drones Power Line Monitoring India 220|Sterlite Power. (n.d.). Retrieved May 10, 2020, from https://www.sterlitepower.com/press-release/sterlite-power-and-sharpershape-use-drones-power-line-monitoring-india-220.

41. Uber Elevate may launch aerial taxi service in India. (n.d.). The Economic Times. Retrieved May 10, 2020, from https://m.economictimes.com/small-biz/startups/newsbuzz/uber-elevate-may-launch-aeria 1-taxi-service-in-india/articleshow/65588648.cms.

42. NationalStrategy-for-AI-Discussion-Paper.pdf. (n.d.). Retrieved from https://niti.gov.in/writereaddata/ files/document_publication/NationalStrategy-for-AI-Discussion-Paper.pdf.

Publisher's Note Springer Nature remains neutral with regard to jurisdictional claims in published maps and institutional affiliations. 


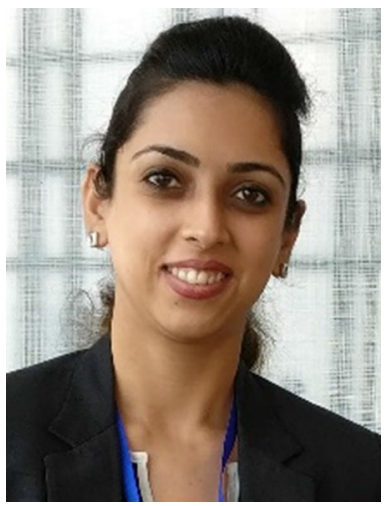

Dr. Purnima Lala Mehta received her bachelor's degree and master's degree in the field of Electronics andCommunications Engineering (ECE) from Bharati Vidyapeeth's College of Engineering for Women (BVCOEW),University of Pune, India, and NorthCap University (formerly ITM University), Gurgaon, India respectively. Shehas received Doctor of Philosophy (Ph.D.) degree, in the field of "Wireless Cellular Communications throughAerial Drones" from one of the ranked universities in the world - Aarhus University, Denmark.On the academic work front, she has been working as an Assistant Professor since July 2012 and has over 8 yearsof teaching and research experience including international exposure at countries like Denmark, Germany, China,Portugal, etc. She has published several peer reviewed journal/ conference papers and book chapters and editedbooks. With regard to one of her research papers she has been recognized under "Quarterly Franklin Membership'from London Journals Press. She has contributed as a Resource Person/Session-Chair in International/Nationalconferences and workshops. She has been invited as a speaker to talk about her research work on drone-basedcommunications at national/international conferences, FDPs and other college events. She is an official Reviewerat Wireless Personal Communications (WPC), Springer. She has also reviewed papers for IEEE VehicularTechnology Magazine and conducted some peer book reviews as well. She is a Member of IEEE and Life Memberof IETE. Her research interests include the areas of Mobile Computing, Aerial Drone based WirelessCommunications, Wireless Ad-Hoc Networks, Millimeter Wave Communications, Future Generations ofCommunications, and Business Modelling.

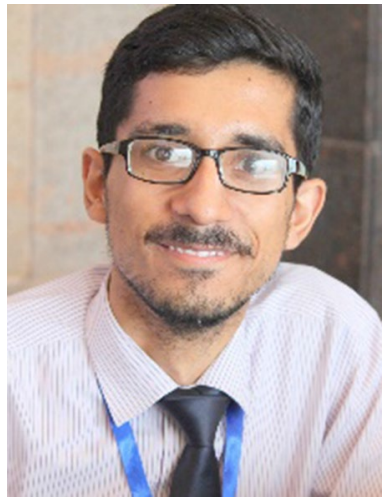

Mr. Ramneek Kalra is currently a Project Engineer at Wipro, India. He is currently holding responsibilities as IEEEImpact Creator, Brand Ambassador \& Young Professional. He is one of the most enthusiastic volunteers in IEEEBrand Ambassador Program through which he is connected with eminent volunteers from Sections including IEEEJordan, Tunisia, Bangladesh, Sri Lanka and more. He has been entitled by Dr. J.K Pal Award from IEEE DelhiSection for his continuous volunteering work. In parallel to IEEE, he is also a proactive member of Human Circle\& Obama Foundation. He always motivates everyone to follow their own passion and how to develop skills toenhance the existing knowledge bank in achieving one's vision. His research domain includes Fog/CloudComputing and he is fond of solving real-world problems around him through his technical stack skills.

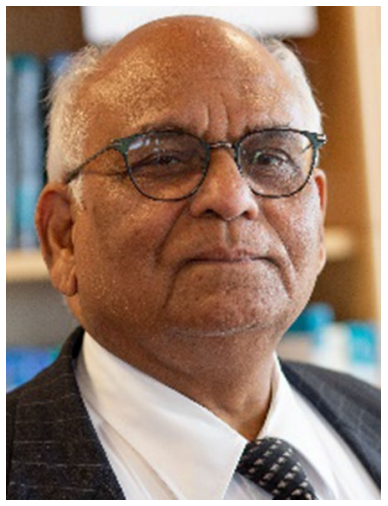

Dr. Ramjee Prasad Fellow IEEE, IET, IETE, and WWRF, is a Professor of Future Technologies for Business Ecosystem Innovation (FT4BI) in the Department of Business Development and Technology, Aarhus University, Herning, Denmark. He is the Founder President of the CTIF Global Capsule (CGC). He is also the Founder Chairman of the Global ICT Standardization Forum for India, established in 2009. He has been honored by the University of Rome "Tor Vergata", Italy as a Distinguished Professor of the Department of Clinical Sciences and Translational Medicine on March 15, 2016. He is an Honorary Professor of the University of Cape Town, South Africa, and the University of KwaZulu-Natal, South Africa. He has received Ridderkorset of Dannebrogordenen (Knight of the Dannebrog) in 2010 from the Danish Queen for the internationalization of top-class telecommunication research and education. He has received several international awards such as IEEE Communications Society Wireless Communications Technical Committee Recognition Award in 2003 for making contribution in the field of "Personal, Wireless and Mobile Systems 
and Networks", Telenor's Research Award in 2005 for impressive merits, both academic and organizational within the field of wireless and personal communication, 2014 IEEE AESS Outstanding Organizational Leadership Award for: "Organizational Leadership in developing and globalizing the CTIF (Center for TeleInFrastruktur) Research Network", and so on. He has been the Project Coordinator of several EC projects namely, MAGNET, MAGNET Beyond, eWALL. He has published more than 50 books, 1000 plus journal and conference publications, more than 15 patents, over $140 \mathrm{Ph} . \mathrm{D}$. Graduates and a larger number of Masters (over 250). Several of his students are today worldwide telecommunication leaders themselves. 